\title{
THE USE OF ALOE CONSTITUENTS IN SELF-ADMINISTERED CANCER TREATMENT
}

\author{
KELSIE E.A. GILLIES ${ }^{1}$ and JONATHAN BLAY*123 \\ Departments of ${ }^{1}$ Pharmacology, ${ }^{2}$ Pathology and ${ }^{3}$ Biology, \\ Dalhousie University, Halifax, Nova Scotia, Canada B3H 1X5
}

\begin{abstract}
Complementary and alternative medicines (CAMs) include many different biologic substances that may be ingested or applied topically in an effort to mitigate disease. One source of such substances is the Aloe, a plant that has been used since antiquity to treat a multitude of conditions, and which is now being touted as a potential natural aid in the fight against cancer. There are many different classes of nutrient and modulatory chemicals isolated from Aloe, and some have now been investigated for their anticancer activities. This review will focus on the anticancer properties of four main Aloe components - aloe-emodin, aloin, acemannan and $\beta$-sitosterol - in relation to their activities against cells in human cancers and potential abilities to interfere with conventional chemotherapeutics. We build upon this background to consider the validity for Aloe in cancer care. It is evident, after considering both in vitro and in vivo findings, that there needs to be further independent studies examining the safety and efficacy of ingestion of Aloe products for human use, proper standardization of product content, and systematic identification and characterization of the wide variety of Aloe constituents.

Aloe is a genus of perennial succulent plants that thrive in hot, dry climates (Choi et al., 2002; Molassiotis et al., 2005). As with many plants, its cosmetic and health-related potentials have been explored since antiquity, and it finds current use in a multitude of cosmetic, dermatologic and other healthcare products (Reynolds and Dweck, 1999; Ulbricht et al., 2007). However, more recently it has fallen into that group of biologics that have found favour in the popular view as a natural remedy for chronic diseases such as cancer. In this review we explore the emerging issue of 'natural medicines', the anticancer activities reported for Aloe itself, and provide a perspective on whether Aloe has a place in rational support of the cancer patient.

Keywords: Natural products, alternative medicine, aloe, aloe-emodin, aloin, acemannan, cancer.
\end{abstract}

* Author to whom correspondence should be addressed: jonathan.blay@dal.ca. 


\section{COMPLEMENTARY AND ALTERNATIVE MEDICINE}

The group of agents and practices that falls outside of conventional western medicine is usually referred to as complementary and alternative medicine (CAM). There is varied opinion as to what practices and ideas fall under this broad term (Tascilar et al., 2006). According to the National Center for Complementary and Alternative Medicine (NCCAM), a division of the National Institutes of Health in the United States, CAM is "a group of diverse medical and health care systems, practices and products that are not generally considered part of conventional medicine" (NCCAM, 2011). NCCAM refers to conventional medicine as that which is practiced by individuals with either medical doctor or doctor of osteopathy degrees, along other health care professionals such as nurses, physiotherapists and psychologists (NCCAM, 2011).

The Canadian Cancer Society (CCS) makes a clear distinction between the 'complementary' and 'alternative' components of CAM (CCS, 2010). It defines complementary medicine similarly to NCCAM as "any practice, therapy or product that is not considered conventional medicine for cancer care" (CCS, 2010). Although many Canadian medical schools offer some training in complementary medicine practices, these practices are not conventionally used to treat cancer. Nevertheless, complementary medicine practices may be combined with standard patient care treatments to help alleviate side effects caused by cancer treatment (CCS, 2010). However, alternative medicine by this definition is used instead of conventional, standard patient care treatments (CCS, 2010). CCS emphasizes the fact that alternative therapies are often based on observations lacking any scientific base (CCS, 2010). Regardless, most definitions of CAM refer to the same general principle of practicing wellness while being treated for a disease, and not necessarily adopting practices employed by conventional medicine.

The varied definitions assigned to CAM make interpretation of surveys on the use of these therapies difficult (Tascilar et al., 2006). Nevertheless, many statistics have been published as to the prevalence of CAM in society worldwide. In a key systematic literature review of this topic, Harris and Rees reported that only three of the 12 studies they surveyed produced reliable prevalence data (Harris and Rees, 2000). In a population survey, MacLennan and colleagues determined that nearly $50 \%$ of all South Australian residents used 
at least one non-medically prescribed CAM, whereas approximately $20 \%$ had sought help from a naturopath or other CAM practitioner (MacLennan et al., 1996). This substantial prevalence of CAM is seen amongst all developed nations and has been increasing since the latter part of the 20th century. Between 1990 and 1997, the number of Americans that used CAM increased from 32 to $42 \%$. Over the same period, patient inquiries about CAM to both medical doctors and CAM practitioners increased from 8 to 14\% (Eisenberg et al., 1998; Eisenberg et al., 1993). Currently, almost 4 out of 10 adults say they have used CAM in the past 12 months (Barnes et al., 2008). This activity involves substantial expenditure that is also rising. Over the period 1997-2007, money spent on CAM-related therapies in the United States increased from just over \$21 billion to nearly \$34 billion (Eisenberg et al., 1998; Nahin et al., 2009). Because Canadian statistics commonly mirror those of the United States, it is evident that many individuals seek benefit from CAM-related therapies (McFarland et al., 2002).

Cancer patients are no less likely to use CAM. In a worldwide systematic review of 26 studies in 1998, approximately $31 \%$ of adult cancer patients were found to have used CAM therapies at some point after being diagnosed (Ernst and Cassileth, 1998). This may be an underestimate for the more developed nations. The data are very variable depending upon geographical location, but more recent data from North America suggest that between 25 and $84 \%$ of cancer patients in the United States have used some sort of CAM therapy after their diagnosis (Tascilar et al., 2006).

Arguably, the potential impact of ingested natural materials may be greater for cancers of the gastrointestinal tract. Tough and colleagues studied CAM use among colorectal cancer patients in Alberta (Tough et al., 2002). The overall prevalence was $49 \%$ and the form of CAM use included psychological and spiritual therapies (65\%), vitamins and minerals (46\%) and herbal supplements (42\%) (Tough et al., 2002). Thus, although noninvasive practices (e.g., psychosocial and spiritual therapies) are most frequently associated with CAM, ingestion or topical application of biological substances accounts for a large portion of CAM use. The use of biological products in cancer has also risen significantly since the early 1990s (Cassileth and Deng, 2004; Cauffield, 2000; Molassiotis et al., 2005). Because each of these substances has the potential to interact with conventional chemotherapeutic agents, 
it is important to analyze the consequences of using CAM-related biological substances while receiving chemotherapy.

\section{ALOE: ITS HISTORY AND USE IN MEDICINE}

Aloe is a genus of perennial succulent plants that thrive in hot, dry climates (Choi and Chung, 2003; Molassiotis et al., 2005). Although there are nearly 400 species within the Aloe genus, only A. barrbadensis (also known as A.vera) and A. aborescens are used in therapeutic preparations (Moghaddasi and Verma, 2011).

Aloe grows in temperate or tropical areas throughout the world (Moghaddasi and Verma, 2011). It is a common and popular ornamental plant that can survive indoors or in gardens with scarce water supply. Large, agricultural-scale crops of Aloe are usually restricted to favored geographic areas such as Mexico, Africa, India, Australia and some parts of the United States (Florida, along with southern areas of Texas and California) (Moghaddasi and Verma, 2011).

Originally described in the Ebers Papyrus, an ancient Egyptian book of remedies, Aloe was used in antiquity for treating skin infections and constipation (Ulbricht et al., 2007). In 74 AD, the Greek physician Dioscorides documented Aloe as being useful for treating wounds, hair loss, genital ulcers and hemorrhoids (Ulbricht et al., 2007). Several hundred years later on, Arab traders brought Aloe to Asia, and the Spanish introduced it to the Americas in the 16th Century (Ulbricht et al., 2007). The popularity of Aloe rose dramatically in the 1930s as it became used as topical treatment for various forms of dermatitis (Reynolds and Dweck, 1999; Ulbricht et al., 2007). Since the 1930s, Aloe has been incorporated in a multitude of cosmetic, dermatologic and other healthcare products (Reynolds and Dweck, 1999; Ulbricht et al., 2007). However, it is also sold on its own as a therapeutic product, largely due to its roots in traditional medicine.

Following its established record of its use in folk medicine, Aloe is used for a variety of (sometimes contradictory) purposes. Based upon its use in traditional Chinese, Indian (Ayurvedic) and Arab medicine, Aloe is often used to treat constipation (Ulbricht et al., 2007). However, Ayurvedic medicine also indicates that Aloe can be used to regulate menstruation, treat hemorrhoids, rid the body of parasitic worms, and when combined with licorice root, Aloe can be effective against eczema and psoriasis (Ulbricht et al., 2007). Traditional Arab 
medicine, meanwhile, claims Aloe to be effective in the treatment of headaches, fevers, wounds and various forms of infection (Ulbricht et al., 2007). Aloe is a truly versatile plant, if history is our guide.

\section{THE DIFFERENT COMPONENTS OF ALOE}

As evident in Fig. 1, Aloe is a succulent plant with long, fleshy leaves. Parenchymal gel from the center of each leaf can be dried (resulting in Aloe concentrate) or can be diluted with water to make juice products. A sticky, latex-like liquid may also be extracted from the tubules that line each leaf (Moghaddasi and Verma, 2011). Until 2002, when the United States FDA deemed it to be a class III substance such that a prescription or license is needed for legal possession, aloin (responsible for Aloe's laxative effects, due to aloin's anthraquinone moiety (Patel et al., 1989)) was used in many over-the-counter laxatives. Today, manufacturers commonly remove aloin from Aloe preparations due to its potential side effects and insufficient safety data (NCCAM, 2011; Ulbricht et al., 2007).

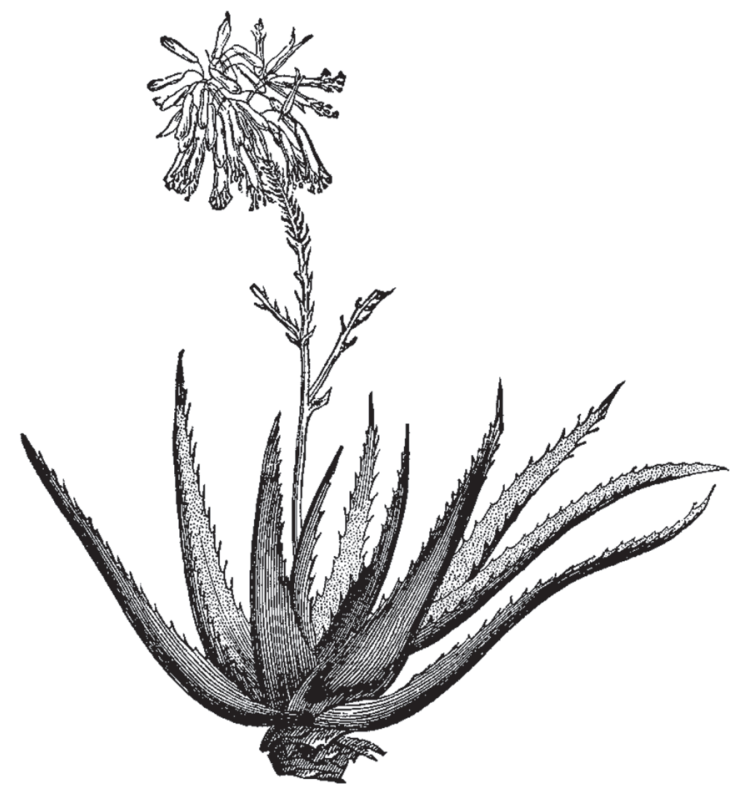

Fig 1 An Aloe vera plant. Note the long, fleshy leaves and the pendulous flowers on a central spike. Modified from (Bianchi, 1997). 
Given the consumer demand and commercial potential for Aloe products, researchers have begun to investigate the biological activity of Aloe leaf components. In part, such investigations seek to validate the claims made by CAM practitioners and the companies producing Aloe products, that Aloe is effective against a variety of diseases. Even a simple online search with "Aloe products" as the keyphrase will identify a variety of websites selling Aloe products for both internal and external use. In this review, our interest focuses on the potential use against cancer. Therefore, we will focus on the particular components of the plant that have been investigated for their anticancer activities.

Aloe contains many different classes of nutrient and modulatory chemicals (Table 1). Attention has particularly focused on the anthraquinones, a class of agents renowned for their various bioactivities (Choi and Chung, 2003). In cancer research, the most widely studied pharmacologically active anthraquinones are aloe-emodin and aloin (Choi and Chung, 2003; Manitto et al., 1990; Reynolds and Dweck, 1999). Both of these compounds can be isolated from the latex leaf lining of Aloe plants (Moghaddasi and Verma, 2011). Aloin and aloe-emodin are structurally related (Fig. 2 A, B). Whereas aloeemodin's structure has two carbonyl $(\mathrm{C}=\mathrm{O})$ groups, the replacement of one carbonyl group with a glucose residue leads to the structure of aloin. Aside from the anthraquinones, some anticancer studies have investigated the saccharide components of the Aloe plant. These have primarily focused upon acemannan, a hydrophilic sugar polymer (Fig. $2 \mathrm{C})$. Acemannan is a polymer of 3-O-acetyl- $\beta$-D-mannopyranose (acetyl-mannose) units linked by $\beta-1 \rightarrow 4$ glycosidic bonds. Amongst

Table 1 Major families of biologically-active chemicals in Aloe.

\begin{tabular}{ll}
\hline Chemical family & Examples \\
\hline Anthraquinones & Aloe-emodin, aloin, aloetic acid \\
Carbohydrates & Acemannan, galactan, xylan \\
Chromones & Neoalosin A, isoabaichrome, 8 -C-glucosyl-noreugenin \\
Enzymes & Amylase, catalase, superoxide dismutase \\
Ions & Calcium, iron, potassium \\
Organic compounds & Lignins, salicyclic acid, potassium sorbate \\
Proteins & Lectin, lectin-like substance \\
Saccharides & Acemannan, mannose, glucose, aldopentose \\
Vitamins & Folic acid, vitamins A, B12, C and E \\
Hormones & Auxins, gibberellins, $\beta$-sitosterol \\
\hline
\end{tabular}

Modified from (Moghaddasi and Verma, 2011). 


\section{A. Aloe-emodin}<smiles>O=C1c2cccc(O)c2C(=O)c2c(O)cc(CO)cc21</smiles>

\section{B. Aloin}

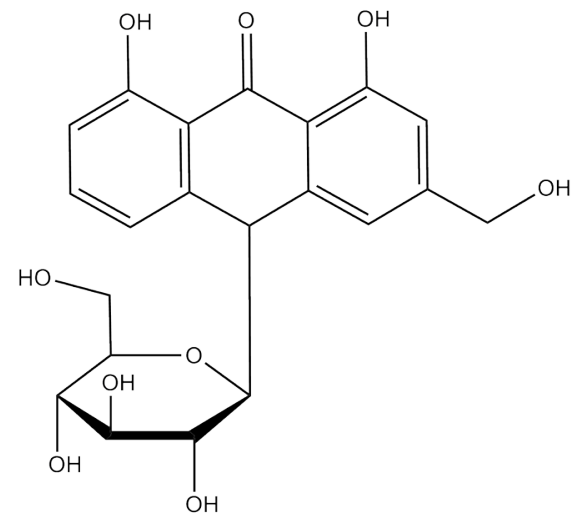

\section{Acemannan}
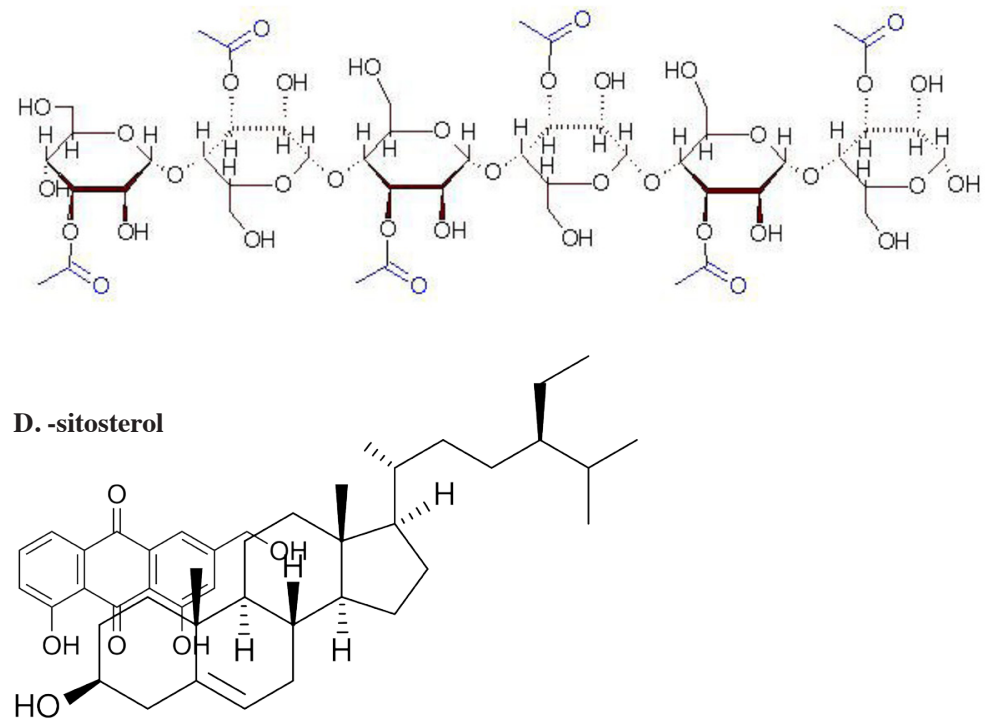

Fig 2 Chemical structures of the key bioactives in Aloe vera. 
the low-molecular-weight substances that have been identified within Aloe is $\beta$-sitosterol, one of several phytosterols (plant sterols) that has a structure very similar to that of cholesterol (Fig. 2 D). This review will focus upon the reported anti-cancer activities of these four principal components: Aloe-emodin, aloin, acemannan and $\beta$ sitosterol. Many different potential cellular effects have been noted in an array of experimental systems; some of the more significant recent findings are summarised in Table 2 . There is a great diversity in terms of available information (e.g. the cellular sources studied and the assays used) and considerable disparity in the amount of data for different Aloe constituents (e.g. there are 18 different studies on aloe-emodin, and just a single relevant study for acemannan). There is also substantial variability in the sources of the materials tested, the degrees of purity and the active concentrations tested. It is therefore important to understand the full picture of activities that have been identified (Table 2).

\section{POTENTIAL ACTIVITIES OF ALOE COMPONENTS IN CANCER}

\section{Activities of Aloe-emodin}

Aloe-emodin has been heralded as a novel potential chemotherapeutic drug due to its ability to modulate the cell cycle and cell proliferation, effects that are mediated by the action of aloe-emodin on protein kinases $\mathrm{C}$ (PKC) a family of 10 signaling enzymes that are important in the release of hormones, cell division and tumor growth (Acevedo-Duncan et al., 2004; Blobe et al., 1994). Human glioma cells exposed to aloe-emodin were unable to progress through the DNA synthesis phase (S phase) of the cell cycle and cell proliferation was inhibited (Acevedo-Duncan et al., 2004). The activity of all PKC isozymes except PKC- $\mathrm{l}$ (the isozyme related to protection of a cell against apoptosis) decreased upon exposure of the cells to aloeemodin. Aloe-emodin concurrently increased the tendency of cells to enter apoptosis (a form of programmed cell death) by modulating the balance of peptidases that promote apoptosis (e.g., caspase-7) and the apoptosis inhibitor survivin (Acevedo-Duncan et al., 2004).

Investigations in cells from a variety of neoplasias show a consistent action of aloe-emodin in inhibiting cell proliferation and enhancing apoptosis through pathways involving PKC. In human lung squamous 


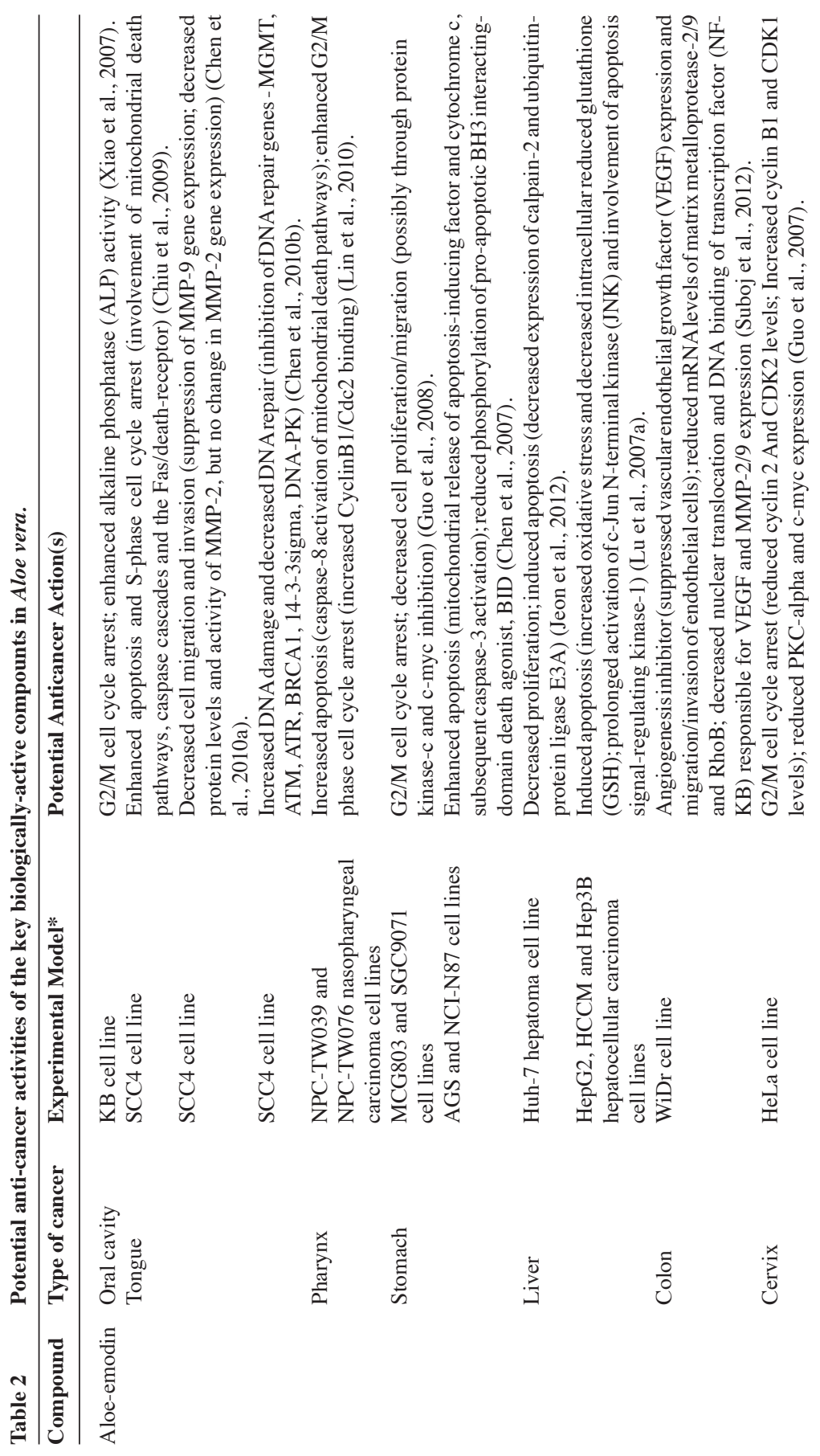




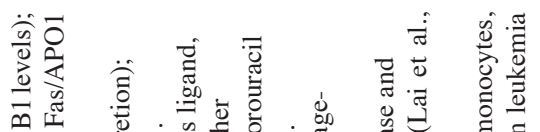

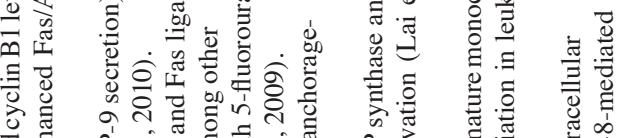

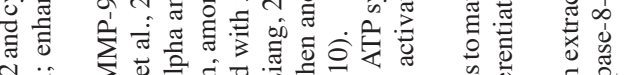

ปั.

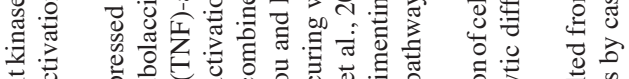

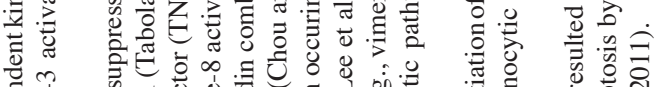

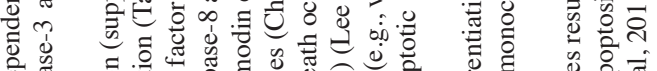

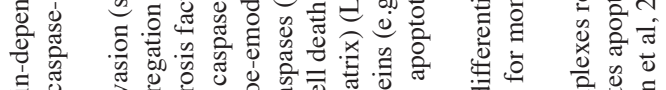

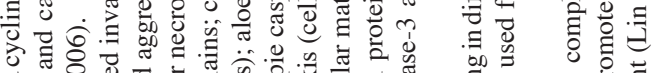

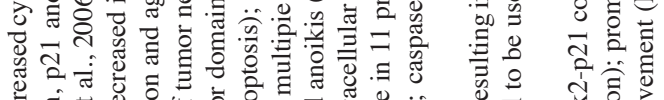

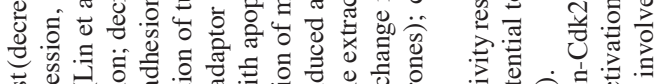

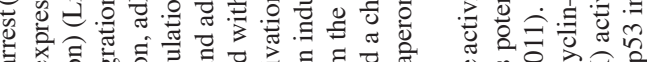

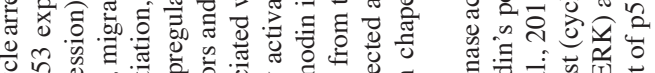

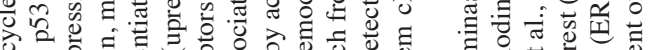

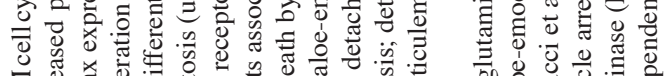

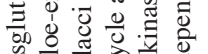

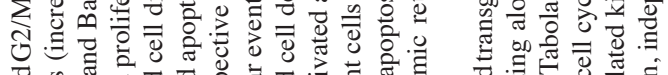

उ.

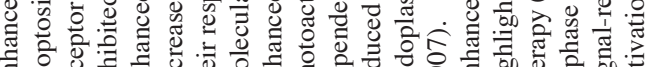

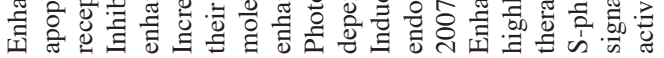

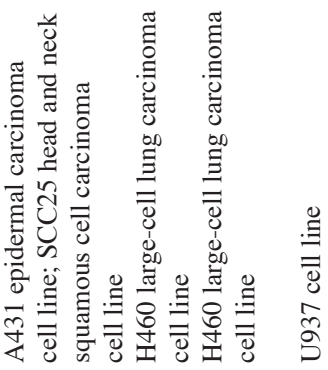

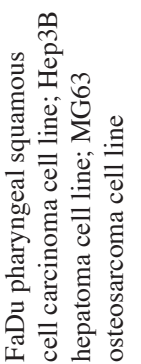

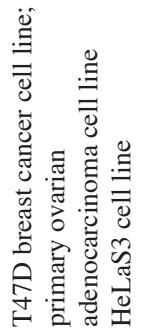

$\frac{\overrightarrow{0}}{\frac{\pi}{n}}$

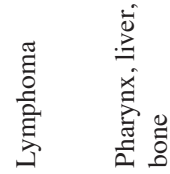

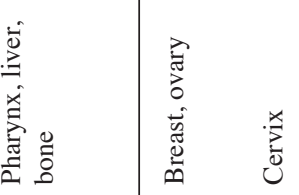

先 


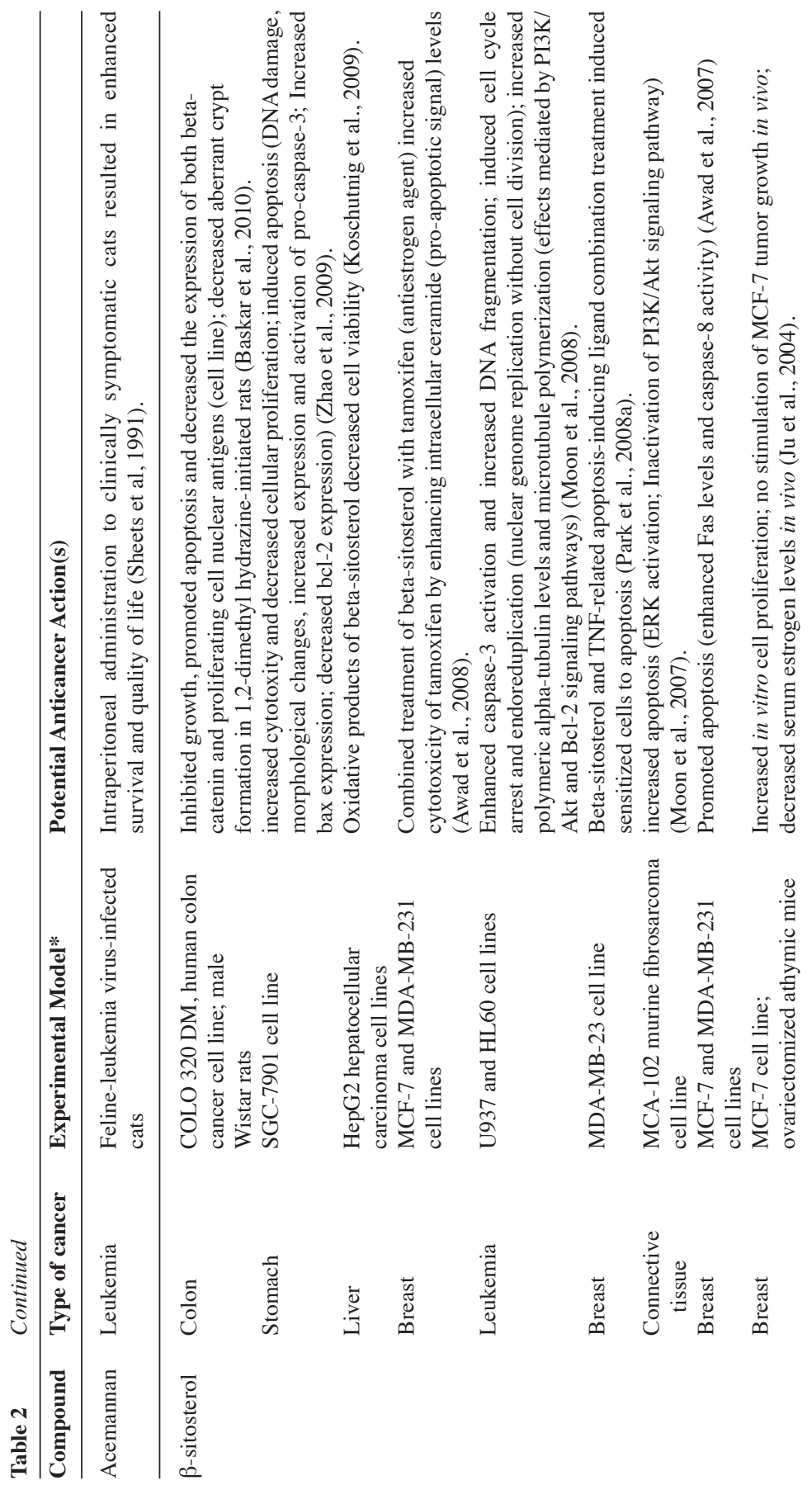




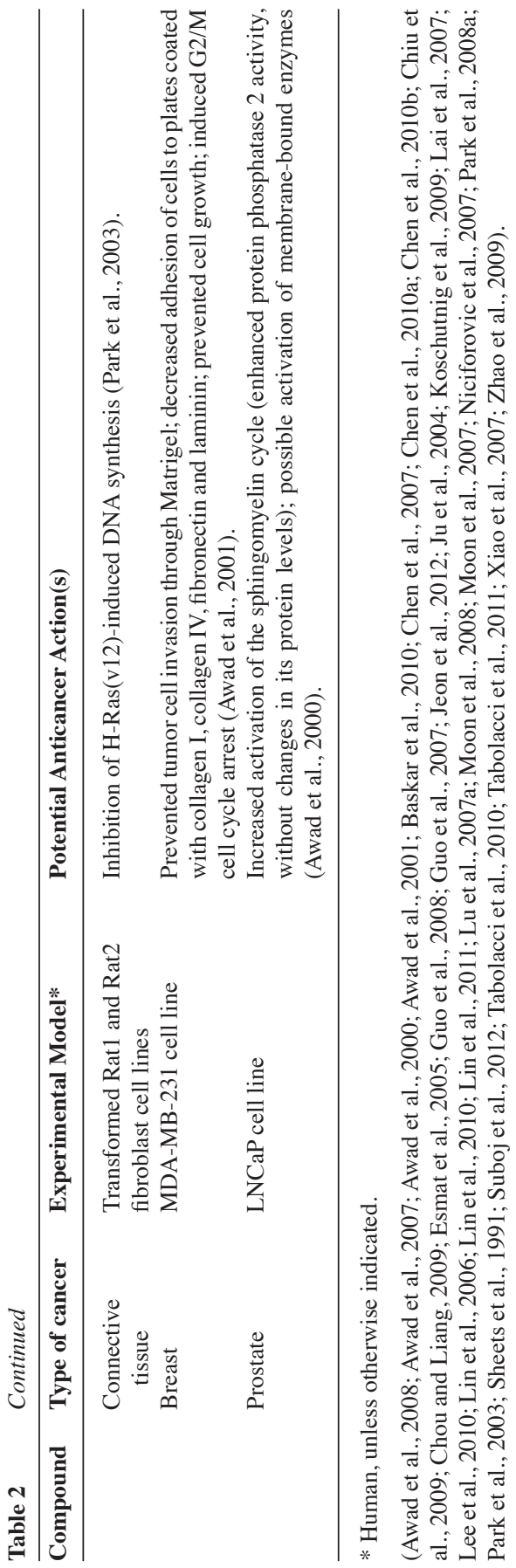


carcinoma and non-small cell carcinoma cell lines, aloe-emodin provoked apoptosis alongside a decrease in expression of two PKC isozymes $(\delta$ and $\varepsilon$ ) and an increase in the apoptosis effector caspase, caspase-3 (Lee, 2001). Similarly, emodin isolated from rhubarb (Rheum palmatum) and structurally similar to aloe-emodin induced apoptosis in a human leukemia cell line by means of a mechanism that depended on caspase-3 (Chen et al., 2002). Therefore, aloe-emodin initiates PKC-dependent signalling pathways that lead to cell death in a variety of cancer cell lines.

Interestingly, aloe-emodin was able to hinder cell proliferation in one human liver cancer cell line (HepG2) and induce apoptosis in another (Hep3B) (Kuo et al., 2002). Further dissection of the mechanism identified p53 and p21 as major players. In the HepG2 cell line, aloe-emodin exposure resulted in $\mathrm{p} 53$ expression that led to increased p21 expression. The protein $\mathrm{p} 21$ is a cyclin-dependent kinase inhibitor and interacts with cyclin-dependent kinases that regulate cell cycle progression at the G1 phase (Kuo et al., 2002). The G1 checkpoint is when the cell interprets a number of incoming signals that determine whether or not it divides (Massague, 2004). Consequently, increased p21 expression in HepG2 cells causes G1 cell cycle arrest. Additionally, aloe-emodin prevents DNA synthesis by upregulation of both p16 and retinoblastoma protein, two important tumor suppressor proteins (Lu et al., 2007b).

However, Hep3B cells do not express p53 to trigger this cascade of events leading to G1 cell cycle arrest (Kuo et al., 2002). In these cells, apoptosis was induced by increased expression of Bax, a proapoptotic protein that is regulated by $\mathrm{p} 21$ in a p53-independent manner (Kuo et al., 2002).

Aloe-emodin has effects on other molecular targets in HepG2 cells. It upregulates proteins associated with oxidative stress and increases the amount of intracellular reactive oxygen species (Lu et al., 2007b). Furthermore, aloe-emodin inhibits cell migration by upregulating nonmetastastic gene 23, an important metastasis inhibition factor (Lu et al., 2007b). Upregulation of the Fas receptor, a member of the tumor necrosis factor (TNF) receptor family, on HepG2 cells has been documented as well (Jiang et al., 1999; Kuo et al., 2002). Fas modulates apoptosis upon binding FasL, its endogenous ligand (Jiang et al., 1999; Kuo et al., 2002). This response leads to mechanisms that overlap with those triggered by conventional chemotherapeutic drugs. 
The data on selective toxicity of aloe-emodin against different cancers are somewhat contradictory because they demonstrate activity of aloe-emodin against some experimental cancer cell lines within a tumour type, but not others. Some studies are highly encouraging. In one study for example (Pecere et al., 2000), aloe-emodin was found to be active against neuroectodermal tumor cells in both tissue culture and animal models, and caused cell death (e.g., cell shrinkage, membrane blebbing and nuclear fragmentation were observed - all of which are morphological features of apoptotic cells). However, growth of human hematopoietic progenitors and normal fibroblasts was not inhibited by aloe-emodin (Pecere et al., 2000). In fact, hematopoietic cells were not affected at concentrations more than 100 times higher than those required to inhibit neuroectodermal tumor cell growth (Pecere et al., 2000). This observation is especially important because high-dose chemotherapy is often associated with neutropenia, a dose-limiting toxicity (Lyman et al., 2005). In severe combined immunodeficiency (SCID) mice, there was no evidence of acute or chronic toxicity of aloe-emodin injected subcutaneously at the highest concentration that could be dissolved in an aqueous solution $(50 \mathrm{mg} / \mathrm{kg} / \mathrm{day}$ ) (Pecere et al., 2000). Unfortunately, in the same study, it was also found that aloe-emodin failed to inhibit the growth of epithelial and bloodderived tumor cell lines (e.g., T-cell leukemia, colon adenocarcinoma and cervix epithelial carcinoma cells), suggesting that any selectivity is based upon cell type rather than whether the target cell is normal or malignant (Pecere et al., 2000).

Of significant concern are observations that in certain circumstances, aloe-emodin may enhance tumor cell growth. For example, it was found to increase the growth of colorectal carcinoma cells (Schorkhuber et al., 1998). After chemical modification by intestinal bacteria, aloe-emodin becomes a strong laxative (Schorkhuber et al., 1998). Continued use of laxatives containing aloe-emodin has been associated with many adverse side effects, including the risk of developing colon cancer in experimental models (Muller et al., 1996; Schorkhuber et al., 1998). It has been suggested that one detrimental action of aloe-emodin might be its ability to increase secretion of urokinase, an enzyme that can digest extracellular matrix, which can increase cell proliferation and, in the context of neoplasia, could also promote metastasis from the colon (Schorkhuber et al., 1998).

Whereas Aloe components (most notably aloe-emodin) have been shown by Ames testing to possess mutagenic and possible carci- 
nogenic potential in vivo, animal studies have not yet unanimously demonstrated these findings (Brusick and Mengs, 1997; Mueller et al., 1998). It has also been suggested that aloe-emodin might be genotoxic by hindering the interaction of topoisomerase II with DNA (Muller et al., 1996). Although topoisomerase II inhibition as such is a cytotoxic mechanism exploited by anti-cancer drugs such as etoposide, improper topoisomerase II function may lead to mutations and chromosomal translocations as have been observed in some forms of leukemia (McClendon and Osheroff, 2007; Muller et al., 1996; van Maanen et al., 1988).

Although many researchers believe that laxatives containing aloeemodin may increase an individual's risk of developing colorectal cancer, other data from human studies show no significant risk of long-term (up to 20 years) laxative use (Nusko et al., 2000). Therefore, it is not conclusive that aloe-emodin-containing laxatives may increase the risk of developing colorectal cancer. Indeed, it is possible that they may instead play a protective role through their suppressive effects on $\mathrm{N}$-acetyltransferases (NATs). NATs are responsible for catalyzing metabolic cascades induced by acrylamine compounds, such as those found in cooked meat (Chung et al., 2003). Through their bioactivation (involving $\mathrm{N}$-acetylation reactions) and detoxification pathways (involving $\mathrm{O}$-acetylation reactions), these enzymes create intermediate metabolites capable of forming adducts with DNA, which can lead to various forms of cancer (Chung et al., 2003). Aloe-emodin decreases NAT activity, likely by binding to the enzyme-substrate complex inhibiting NAT activity as a possible non-competitive inhibitor. The net effect is to hinder the formation of DNA adducts after acrylamine exposure (Chung et al., 2003).

Several studies have tried to quantify the levels of aloe-emodin that can be attained within the human body and therefore interact with cells following ingestion. Therapeutic doses of laxatives containing aloe-emodin administered repeatedly in 10 healthy volunteers resulted in aloe-emodin being undetectable in blood samples collected within $96 \mathrm{~h}$ of receiving the first dose (Krumbiegel and Schulz, 1993). A kinetic study using two in vitro intestinal models - an everted rat gut sac and a monolayer of differentiated and absorptive cells similar to those in the small intestine (Caco-2 cells) also tried to determine the fate of aloe-emodin when ingested (Park et al., 2009). Uptake of aloe-emodin by intestinal epithelial cells was demonstrated by both approaches. After incubation with 5 to $50 \mu \mathrm{M}$ of aloe-emodin, the 
rate of aloe-emodin absorption was similar between the two models, and reached saturation near the $50 \mu \mathrm{M}$ treatment. The percentage of aloe-emodin that was absorbed ranged from $6.6 \%$ to $11.3 \%$ (Park et al., 2009) This ready uptake is likely due to aloe-emodin's relatively high affinity for phospholipid membranes (Park et al., 2008b). In addition, aloe-emodin may interact with certain transporters, such as the sodium dependent glucose transporter-1 that could transport aloe-emodin into the cell unchanged (Park et al., 2008b). Additionally, Caco-2 cells may metabolize aloe-emodin by phase II metabolic reactions involving glucuronidation or sulfation and in this context it has been found that nearly $19 \%$ of glucuronidated or sulfated aloeemodin was absorbed (Park et al., 2009). Metabolism in vivo is mostly in the liver, and aloe-emodin can be converted to 2-hydroxyemodin by cytochrome P450 1A2 (Mueller et al., 1998; Park et al., 2008b).

Whereas aloe-emodin has been studied for its ability to regulate cell cycle and proliferation through its interaction with a variety of molecular targets, literature underlining aloe-emodin's potential carcinogenic effects make it unclear as to whether or not this compound can be used for its anticancer properties. However, research associated with aloin, and anthraquinone similar to aloe-emodin, has also been conducted.

\section{Activities of Aloin}

Aloin (Fig. 2 B) is a mixture of two diasteromers, aloin A and aloin $\mathrm{B}$, which differ depending on whether the sugar moiety is above (aloin A) or below (aloin B) the plane of the anthroquinone (Park et al., 2008b). Because aloin can be converted to aloe-emodin anthrone by intestinal bacteria in humans, these two compounds share similar biological effects after ingestion, such as their abilities to act as potent laxatives (Akao et al., 1996) (Choi and Chung, 2003). Whereas the majority of anticancer research has focused on the pharmacological effects of aloe-emodin, several anticancer properties of aloin have also been investigated.

Just as for aloe-emodin, aloin has been linked with the ability to trigger apoptosis. Using Jurkat T-lymphocytes, aloin was shown to disrupt cell membrane integrity and interfere with mitochondrial membrane potential, both of which are hallmarks of apoptosis (Buenz, 2008). Using DNA-staining techniques, aloin was also found to increase the proportion of cells at the G2 cell cycle phase that precedes cell division (Buenz, 2008). These apoptotic and antiproliferative effects 
required large doses within the range of $100-1000 \mu \mathrm{g} / \mathrm{ml}$. The huge variabiity in doses of aloin (or other agents) may reflect the absence of enzymes that may convert aloin to active metabolites, which are often found in the liver. However, more studies are required to not only determine, but also characterize aloin metabolites in vivo and in vitro (Buenz, 2008).

Aloin has been shown to be cytotoxic in two human breast cancer cell lines (MCF-7 and SKBR-3) (Esmat et al., 2006). Similar to aloeemodin, there seems to be a link with topoisomerase II, and also with the HER-2/Erb-2 oncogene, which specifies an aberrant growth factor receptor. Topoisomerase II $\alpha$ and HER-2/Erb-2 genes are often coamplifed in breast cancer, and the amplification of topoisomerase II $\alpha$ together with HER-2/Erb-2 relates to the effectiveness of aloin action (Esmat et al., 2006). MCF-7 cells (with no overexpression of either Erb-2 or topoisomerase II $\alpha$ ) were more sensitive to the cytotoxic effects of aloin (half-maximal inhibitory concentration $\left(\mathrm{IC}_{50}\right) 60 \mu \mathrm{g} / \mathrm{ml}$, compared with $150 \mu \mathrm{g} / \mathrm{ml}$ ) than SKBR-3 cells (with coamplification of Erb-2 and topoisomerase II $\alpha$ ) (Esmat et al., 2006). The effect of aloin in MCF-7 cells was to disrupt the cell cycle and induce apoptosis by inhibiting cyclin B1 (a regulatory protein in mitosis) expression, following inhibition of topoisomerase II $\alpha$ expression (Esmat et al., 2006). SKBR-3 cells exhibited a lesser effect consistent with the slight decrease in topoisomerase II $\alpha$ expression. Clearly, the effect of aloin on breast cancer cells depends on the precise phenotype of the cancer cells. It also appears that this compound exerts its action through a variety of mechanisms.

The intestinal epithelial absorption of aloin in everted rat gut sac and Caco- 2 cell models is similar to that of aloe-emodin, even though there is no bacterial conversion to the latter in these systems. The absorption of aloin was between $5.5 \%$ and $6.6 \%$, with approximately $18.2 \%$ being absorbed if in the glucuronidated or sulfated form (Park et al., 2009). To assess aloin's bioavailability in vivo, plasma, tissue and urine concentrations of aloin were measured in rats that were given $11.8 \mathrm{~g} / \mathrm{kg}$ of aloin by gavage (Park et al., 2008b). This dose was chosen based on previous studies that had established $11.8 \mathrm{~g} / \mathrm{kg}$ as the lowest observed adverse effect level. Aloin was detected in the plasma, with its peak concentration $(59.1 \mathrm{ng} / \mathrm{ml})$ being reached after $1 \mathrm{~h}$. Aloin reached its peak liver and intestine concentrations in $30 \mathrm{~min}$, with the liver concentration being approximately $78 \mathrm{ng} / \mathrm{ml}$ and that of the intestine being roughly $100 \mathrm{ng} / \mathrm{ml}$. The peak kidney 
concentration (nearly $13 \mathrm{ng} / \mathrm{ml}$ ) occurred after $5 \mathrm{~h}$ and the amount of aloin that had accumulated in the urine over a 24-h period was estimated to be $0.03 \%$ of the initial dose (Park et al., 2008b). Metabolism appears to be primarily hepatic (Park et al., 2008b).

The studies using both aloe-emodin and aloin show a substantial disparity between the concentrations that are tested in vitro to identify putative anti-cancer effects, and those that are attainable in vivo even with generous oral dosing. The work of Park and colleagues (Park et al., 2008b), with oral dosing that would equate to a daily intake of $0.83 \mathrm{~kg}$ of aloin per day in the standard $70 \mathrm{~kg}$ human, yielded systemic levels of no more than $100 \mathrm{ng} / \mathrm{ml}$. Yet some of the in vitro studies with cancer cell lines have used concentrations in culture as high as $1000 \mu \mathrm{g} / \mathrm{ml}$ (Buenz, 2008), that is 10,000-fold higher than are readily attainable. While the use of anthraquinones at such high concentrations in culture may reveal useful activities of molecular motifs that could be refined to eventually produce a worthwhile drug, it has very little value in informing us of the value of Aloe itself if ingested by an actual cancer patient. More focused efforts on the application of Aloe components are underway: investigations are being conducted to compare aloin's cardiotoxicity to that of commonly used chemotherapeutic agents such as doxorubicin, an anthracycline that often induces cardiotoxicity (Esmat et al., 2006); and researchers are attempting to modify aloin's chemical structure in order to heighten its cytotoxic effects (Kumar et al., 2010).

\section{Activities of Acemannan}

Acemannan, which is isolated from the gel of the Aloe plant, has been shown to activate macrophages both in vitro and in vivo (Djeraba and Quere, 2000; Moghaddasi and Verma, 2011; Zhang and Tizard, 1996), and might therefore potentially promote the action of tumourassociated macrophages. Acemannan binds to protein receptors on the macrophage cell surface (Djeraba and Quere, 2000; Zhang and Tizard, 1996), facilitating the internalization of acemannan, which in turn results in macrophage activation. Such activation is associated with the release of cytokines that have many actions, including the enhancement of T-cell proliferation and increased T-cell-mediated cytotoxicity (Djeraba and Quere, 2000; Karaca et al., 1995; Zhang and Tizard, 1996).

Macrophage activation is often measured in terms of nitric oxide (NO) production (Djeraba and Quere, 2000; Karaca et al., 1995; Zhang 
and Tizard, 1996). NO regulates major histocompatibility cell (MHC) surface antigens that are required for antigen presentation and the recognition of foreign antigens, such as those that may be present on a cancer cell (Djeraba and Quere, 2000; Zhang and Tizard, 1996). Furthermore, release of NO has been shown to inhibit the DNA synthesis of tumor cell lines (Drapier and Hibbs, 1988).

Although mechanisms of acemannan action are still being investigated, it appears that acemannan principally functions to enhance immune mechanisms (e.g., macrophage activation, immune system stimulation and enhanced release of anticancer cytokines) (de Visser et al., 2006; Harris et al., 1991; Peng et al., 1991). This has proven sufficient grounds for it to be used in the treatment of cancer in animals such as cats and dogs (Harris et al., 1991; VPL, 2011). The compound is typically administered by subcutaneous or intramuscular injection, and it is uncertain whether oral doses would be as effective (VPL, 2011). Oral acemannan needs to be broken down by gut flora so that mannose receptors lining gut epithelial cells can transport it into the bloodstream for distribution throughout the body (Flint et al., 2008).

\section{Activities of $\beta$-sitosterol}

Aloe plants contain numerous other components that may exert effects on cell cycle and proliferation. For example, Aloe gel also yields $\beta$-sitosterol, which is partly responsible for Aloe's wound healing properties and has been demonstrated to be a potent inducer of angiogenesis (Choi et al., 2002; Lee et al., 1995). This is thought to occur by the ability of $\beta$-sitosterol to increase pro-angiogenic proteins such as vascular endothelial growth factor (VEGF), Flk-1 (a receptor for VEGF), von Willebrand factor and blood vessel matrix laminin (Choi et al., 2002). Because angiogenesis is an essential step in tumour progression since tumors require a blood supply to grow larger or spread to other organs, there is a possibility that $\beta$-sitosterol may promote tumor growth in animal models (Carmeliet and Jain, 2000).

\section{USE OF ALOE IN TREATMENT OF HUMAN CANCERS}

Aloe use, whether for topical purposes or by ingestion, has been a well-established practice in different cultures for many years. Therefore, it is no surprise that even with conflicting reports as to the proposed biological activities of Aloe components and suggestions of interactions of these components with anticancer drugs, cancer 
patients will continue to use Aloe or its components. This may be for hoped-for anti-cancer properties, or to alleviate symptoms of conventional therapies. For example, at the time of writing one website for a company that markets Aloe products makes these comments "Courses of chemotherapy tend to make people feel thoroughly rotten. This particular treatment tends to cause bouts of nausea that negates what little appetite they might have. Drinking gel before, during and after chemotherapy may alleviate these symptoms." (FLAP, 2010).

\section{Evidence for Anti-cancer Activity}

There have been several clinical studies that have looked at possible effects of Aloe in addition to standard chemotherapy. One focused study looked at its use in lung, colorectal, gastric and pancreatic cancer patients in addition to a base of standard-of-care chemotherapy appropriate for the clinical characteristics of each metastastic, solid tumor (Lissoni et al.,2009). A comparison was made between patients who received Aloe in addition to their chemotherapy and patients who did not receive Aloe with their chemotherapy. For patients that received Aloe, an oral dose was given three times each day, beginning six days before the onset of chemotherapy. Aloe administration was continued during chemotherapy and each dose consisted of 300 $\mathrm{g}$ of fresh Aloe leaves together with $500 \mathrm{~g}$ of honey. It was found that Aloe given in conjunction with chemotherapy significantly increased tumor regression and disease control, while also prolonging survival (Lissoni et al., 2009). Furthermore, quality of life increased in patients that received both Aloe and chemotherapy because of decreased asthenia (loss of strength) and increased energy levels (Lissoni et al., 2009). However, this study was not blinded - and it would be hard to blind such a treatment - so that confounding influences such as altered patient behaviour in the treatment group are hard to exclude.

The same investigators also conducted a controlled clinical trial on patients with numerous advanced solid tumors that were refractory to established treatment (Lissoni et al., 1998). In this case, patients were given either melatonin (an immunomodulating hormone produced by the pineal gland) or a combination of melatonin and Aloe. Improvements were reported for the combination of melatonin and Aloe compared with melatonin alone, in partial response ( $8 \%$ vs $0 \%$ ), stable disease (50\% vs $27 \%$ ) and one-year survival rates (Lissoni et al., 1998). 
There is thus some evidence of a beneficial effect of Aloe in advanced cases of human cancer (Lissoni et al., 1998; Lissoni et al., 2009). However, it will be necessary to carry out blinded and randomized trials with at least partially-purified extracts before the evidence is fully convincing.

\section{Possible Interactions with Conventional Drugs}

Because numerous chemotherapeutic drugs (e.g., cisplatin, 5-fluorouracil (5-FU), adriamycin, mitoxanthrone and etoposide) have been found to induce apoptosis in solid tumors and some types of leukemia, some researchers believe it is possible that aloe-emodin may be useful in enhancing their apoptotic response (Fenig et al., 2004; Hickman, 1992; Jiang et al., 1999). However, data relating to this belief are somewhat contradictory because some studies document a cytoprotective effect of aloe-emodin. For example, aloe-emodin reduced cisplatin's ability to trigger apoptosis in certain fibrosarcoma and glioma cell lines (Mijatovic et al., 2005). In these cells, aloe-emodin in fact interfered with cisplatin's ability to activate the extracellular signal-related kinase (ERK) pathway that can promote apoptosis or cell cycle arrest (Cagnol and Chambard, 2010; Mijatovic et al., 2005). The cytoprotective action of aloe-emodin was further examined in comparable fibrosarcoma and glioma cell lines (Harhaji et al., 2007). It was determined that aloe-emodin reduced the cytotoxic effects of TNF, a proinflammatory cy tokine, by decreasing TNF-initiated ERK activation (Harhaji et al., 2007). Therefore, the possibility exists, that aloe-emodin can interfere with conventional drug therapy in addition to having the potential to enhance anti-cancer drug action. This poses something of a dilemma in terms of arguments for a therapeutic effect of ingested aloe-emodin in cancer patients.

\section{Assessment for Dermatologic Benefit}

Perhaps more inherently logical given the wide utility of Aloe in skin care products is the possibility of using Aloe to address dermatological problems incurred during cancer treatment. Aloe gel has been evaluated as a possible agent to prevent dermatitis caused by radiation therapy (Williams et al., 1996). In a first Phase II randomized clinical trial, these investigators tracked the status of skin dermatitis (e.g., severity of dermatitis, time until severe dermatitis occurs and how long severe dermatitis would persist) in female patients receiving chest or breast radiation treatment. It compared the topical applica- 
tion of Aloe to a placebo gel and found no significant differences between the treatment groups. A second trial was conducted with a similar patient cohort to eliminate the possibility that the gel itself might be efficacious, and compared an Aloe gel group against a 'no treatment group'. However, this trial also failed to demonstrate an effect of Aloe, indicating that the dermatitis resulting from radiation therapy (which has a large component of direct cellular damage) is not alleviated by Aloe product. Therefore, these studies would suggest that Aloe is ineffective for dermatological problems associated with cancer treatments.

\section{FUTURE PROSPECTS FOR ALOE IN CANCER TREATMENT}

\section{Is Aloe Useful for Cancer Treatment?}

The situation with Aloe is similar to that of many natural products that have garnered an active following in the general population that arises out of a long history of use extending back to before the emergence of western medicine. It has proven extremely challenging to show effects that will satisfy the demands of evidence-based medicine. Bench science using experimental models has revealed promise for bioactivity of individual components of Aloe, but the evidence is often flawed by the use of doses that are many orders of magnitude above those attainable in the human patient. Research in both cellular and animal models has also suggested possible negative actions of these compounds, leading to toxicities or perhaps even increased cancer risk. This research again may be compromised by the experimental doses, but it is an inevitable truth that any substance that has useful bioactivity will carry a risk of 'off-target' side effects as a result of its activity; there is no assurance that just because something 'is natural' it cannot also be harmful.

Whether or not natural components of Aloe have genuine activity against cancer (or potentially may promote aspects of the disease) is unclear based on both the in vitro and clinical data presented in this review. However, it is evident that - as for many natural sources - the native molecules do have activities against cellular pathways that if appropriately extended, could lead to useful agents to manipulate the cellular response.

Identifying the chemicals within Aloe that might have potential for further study or development will require thorough studies that 
characterize the wide variety of potentially biologically active compounds of the plant. Each of these compounds must be assessed for their effects on cell cycle proliferation. Furthermore, it is likely that interactions between these compounds also influence their respective biological activities.

\section{Safety in Use of Aloe}

Aloe is a popular biologic used by the public in CAM-related approaches to disease treatment, and there are many companies producing Aloe products. It is important for the public to recognize that the composition of these products is highly variable, especially when Aloe extracts are obtained from plants of different geographic origins (Choi and Chung, 2003; Reynolds and Dweck, 1999). There are often poor manufacturing techniques and quality control mechanisms in place to ensure standardized forms of Aloe preparations (Choi and Chung, 2003; Moghaddasi and Verma, 2011; Reynolds and Dweck, 1999). Additionally, poor regulation of Aloe products has prevented CAM practitioners from agreeing on a standard dose that can be efficacious without inducing undesirable side effects (Marcus and Grollman, 2002).

These again are common challenges in the use of whole natural products to self-treat disease. Understanding the biological activities of Aloe constituents, their interactions with conventional medicines, and proper standardization of product content, are essential for the safety of those who take these preparations, irrespective of the contribution they make to alleviating disease.

Acknowledgements K.E.A.G. is supported by the Natural Sciences and Engineering Research Council (NSERC) and the Killam Foundation. J.B. is a Senior Scientist of the Beatrice Hunter Cancer Research Institute, Halifax, Nova Scotia.

\section{REFERENCES}

Acevedo-Duncan, M., Russell, C., Patel, S., and Patel, R. 2004. Aloeemodin modulates PKC isozymes, inhibits proliferation, and induces apoptosis in U-373MG glioma cells. International immunopharmacology. 4: 1775-1784.

Akao, T., Che, Q.M., Kobashi, K., Hattori, M., and Namba, T. 1996. A purgative action of barbaloin is induced by Eubacterium sp. strain BAR, 
a human intestinal anaerobe, capable of transforming barbaloin to aloeemodin anthrone. Biological \& pharmaceutical bulletin. 19: 136-138.

Awad, A.B., Barta, S.L., Fink, C.S., and Bradford, P.G. 2008. betaSitosterol enhances tamoxifen effectiveness on breast cancer cells by affecting ceramide metabolism. Molecular nutrition \& food research. 52: 419-426.

Awad, A.B., Chinnam, M., Fink, C.S., and Bradford, P.G. 2007. betaSitosterol activates Fas signaling in human breast cancer cells. Phytomedicine : international journal of phytotherapy and phytopharmacology. 14: 747-754.

Awad, A.B., Gan, Y., and Fink, C.S. 2000. Effect of beta-sitosterol, a plant sterol, on growth, protein phosphatase $2 \mathrm{~A}$, and phospholipase D in LNCaP cells. Nutrition and cancer. 36: 74-78.

Awad, A.B., Williams, H., and Fink, C.S. 2001. Phytosterols reduce in vitro metastatic ability of MDA-MB-231 human breast cancer cells. Nutrition and cancer. 40: 157-164.

Barnes, P.M., Bloom, B., and Nahin, R.L. 2008. Complementary and alternative medicine use among adults and children: United States, 2007. National health statistics reports: 1-23.

Baskar, A.A., Ignacimuthu, S., Paulraj, G.M., and Al Numair, K.S. 2010. Chemopreventive potential of beta-Sitosterol in experimental colon cancer model--an in vitro and In vivo study. BMC complementary and alternative medicine. 10: 24.

Bianchi, A. 1997. Piante Medicinali e AIDS. Tecniche Nuove.

Blobe, G.C., Obeid, L.M., and Hannun, Y.A. 1994. Regulation of protein kinase $\mathrm{C}$ and role in cancer biology. Cancer metastasis reviews. 13: 411-431.

Brusick, D., and Mengs, U. 1997. Assessment of the genotoxic risk from laxative senna products. Environmental and molecular mutagenesis. 29: 1-9.

Buenz, E.J. 2008. Aloin induces apoptosis in Jurkat cells. Toxicology in vitro : an international journal published in association with BIBRA. 22: 422-429.

Cagnol, S., and Chambard, J.C. 2010. ERK and cell death: mechanisms of ERK-induced cell death--apoptosis, autophagy and senescence. The FEBS journal. 277: 2-21.

Carmeliet, P., and Jain, R.K. 2000. Angiogenesis in cancer and other diseases. Nature. 407: 249-257.

Cassileth, B.R., and Deng, G. 2004. Complementary and alternative therapies for cancer. The oncologist. 9: 80-89.

Cauffield, J.S. 2000. The psychosocial aspects of complementary and alternative medicine. Pharmacotherapy. 20: 1289-1294.

CCS. 2010. Complementary and alternative therapies. Canadian Cancer Society. cancer.ca/Canada-wide/about cancer/treatment/complementary and alternative therapies.aspx [accessed 1 April 2011].

Chen, S.H., Lin, K.Y., Chang, C.C., Fang, C.L., and Lin, C.P. 2007. Aloe-emodin-induced apoptosis in human gastric carcinoma cells. Food 
and chemical toxicology : an international journal published for the British Industrial Biological Research Association. 45: 2296-2303.

Chen, Y.C., Shen, S.C., Lee, W.R., Hsu, F.L., Lin, H.Y., Ko, C.H. and Tseng, S.W. 2002. Emodin induces apoptosis in human promyeloleukemic HL-60 cells accompanied by activation of caspase 3 cascade but independent of reactive oxygen species production. Biochemical pharmacology. 64: 1713-1724.

Chen, Y.Y., Chiang, S.Y., Lin, J.G., Ma, Y.S., Liao, C.L., Weng, S.W., Lai, T.Y., and Chung, J.G. 2010a. Emodin, aloe-emodin and rhein inhibit migration and invasion in human tongue cancer SCC-4 cells through the inhibition of gene expression of matrix metalloproteinase-9. International journal of oncology. 36: 1113-1120.

Chen, Y.Y., Chiang, S.Y., Lin, J.G., Yang, J.S., Ma, Y.S., Liao, C.L., Lai, T.Y., Tang, N.Y., and Chung, J.G. 2010b. Emodin, aloe-emodin and rhein induced DNA damage and inhibited DNA repair gene expression in SCC-4 human tongue cancer cells. Anticancer research. 30: $945-951$.

Chiu, T.H., Lai, W.W., Hsia, T.C., Yang, J.S., Lai, T.Y., Wu, P.P., Ma, C.Y., Yeh, C.C., Ho, C.C., Lu, H.F., Wood, W.G. and Chung, J.G. 2009. Aloe-emodin induces cell death through S-phase arrest and caspase-dependent pathways in human tongue squamous cancer SCC-4 cells. Anticancer research. 29: 4503-4511.

Choi, S., and Chung, M.-H. 2003. A review on the relationship between Aloe vera components and their biologic effects. Semin Integrative Med. 1: 53-62.

Choi, S., Kim, K.W., Choi, J.S., Han, S.T., Park, Y.I., Lee, S.K., Kim, J.S. and Chung, M.H.. 2002. Angiogenic activity of beta-sitosterol in the ischaemia/reperfusion-damaged brain of Mongolian gerbil. Planta medica. 68: 330-335.

Chou, T.H., and Liang, C.H. 2009. The molecular effects of aloe-emodin (AE)/liposome-AE on human nonmelanoma skin cancer cells and skin permeation. Chemical research in toxicology. 22: 2017-2028.

Chung, J.G., Li, Y.C., Lee, Y.M., Lin, J.P., Cheng, K.C. and Chang, W.C. 2003. Aloe-emodin inhibited N-acetylation and DNA adduct of 2-aminofluorene and arylamine $\mathrm{N}$-acetyltransferase gene expression in mouse leukemia L 1210 cells. Leukemia research. 27: 831-840.

de Visser, K.E., Eichten, A. and Coussens, L.M. 2006. Paradoxical roles of the immune system during cancer development. Nature reviews. Cancer. 6: 24-37.

Djeraba, A., and Quere, P. 2000. In vivo macrophage activation in chickens with Acemannan, a complex carbohydrate extracted from Aloe vera. International journal of immunopharmacology. 22: 365-372.

Drapier, J.C., and Hibbs, J.B. Jr. 1988. Differentiation of murine macrophages to express nonspecific cytotoxicity for tumor cells results in L-arginine-dependent inhibition of mitochondrial iron-sulfur enzymes in the macrophage effector cells. J Immunol. 140: 2829-2838. 
Eisenberg, D.M., Davis, R.B., Ettner, S.L., Appel, S., Wilkey, S., Van Rompay, M., and Kessler, R.C. 1998. Trends in alternative medicine use in the United States, 1990-1997: results of a follow-up national survey. JAMA : the journal of the American Medical Association . 280: 1569-1575.

Eisenberg, D.M., Kessler, R.C., Foster, C., Norlock, F.E., Calkins, D.R. and Delbanco, T.L. 1993. Unconventional medicine in the United States. Prevalence, costs, and patterns of use. The New England journal of medicine. 328: 246-252.

Ernst, E., and Cassileth, B.R. 1998. The prevalence of complementary/ alternative medicine in cancer: a systematic review. Cancer. 83: 777-782.

Esmat, A.Y., El-Gerzawy, S.M., and Rafaat, A. 2005. DNA ploidy and $S$ phase fraction of breast and ovarian tumor cells treated with a natural anthracycline analog (aloin). Cancer biology \& therapy. 4: 108-112.

Esmat,A.Y., Tomasetto, C., and Rio,M.C. 2006. Cytotoxicity of a natural anthraquinone (Aloin) against human breast cancer cell lines with and without ErbB-2: topoisomerase IIalpha coamplification. Cancer biology \& therapy. 5: 97-103.

Fenig, E., Nordenberg, J., Beery, E., Sulkes, J., and Wasserman, L. 2004. Combined effect of aloe-emodin and chemotherapeutic agents on the proliferation of an adherent variant cell line of Merkel cell carcinoma. Oncology reports. 11: 213-217.

FLAP. 2010. Cancer care with Forever Living Aloe products. . Forever Living Aloe Products. aloe4us.com/1/post/2010/04/cancel-care-with-foreverliving-aloe-products-dr-peter-atherton.html [accessed 15 April 2011].

Flint, H.J., Bayer, E.A., Rincon, M.T., Lamed, R., and White, B.A. 2008. Polysaccharide utilization by gut bacteria: potential for new insights from genomic analysis. Nature reviews. Microbiology. 6: 121-131.

Guo,J., Xiao, B., Liu, Q., Gong, Z., and Le, Y.2008. Suppression of C-myc expression associates with anti-proliferation of aloe-emodin on gastric cancer cells. Cancer investigation. 26: 369-374.

Guo, J.M., Xiao, B.X., Liu, Q., Zhang, S., Liu, D.H. and Gong, Z.H. 2007. Anticancer effect of aloe-emodin on cervical cancer cells involves G2/M arrest and induction of differentiation. Acta pharmacologica Sinica. 28: 1991-1995.

Harhaji,L., Mijatovic, S., Maksimovic-Ivanic, D., Popadic, D., Isakovic, A., Todorovic-Markovic, B. and Trajkovic, V. 2007. Aloe emodin inhibits the cytotoxic action of tumor necrosis factor. European journal of pharmacology. 568: 248-259.

Harris, C., Pierce, K., King, G., Yates, K.M., Hall, J., and Tizard, I. 1991. Efficacy of acemannan in treatment of canine and feline spontaneous neoplasms. Molecular biotherapy. 3: 207-213.

Harris, P., and Rees, R. 2000. The prevalence of complementary and alternative medicine use among the general population: a systematic review of the literature. Complementary therapies in medicine. 8:88-96.

Hickman, J.A. 1992. Apoptosis induced by anticancer drugs. Cancer metastasis reviews. 11: 121-139. 
Jeon, W., Jeon, Y.K., and Nam, M.J. 2012. Apoptosis by aloe-emodin is mediated through down-regulation of calpain-2 and ubiquitin-protein ligase E3A in human hepatoma Huh-7 cells. Cell biology international. 36: 163-167.

Jiang, S., Song, M.J., Shin, E.C., Lee, M.O., Kim, S.J. and Park, J.H. 1999. Apoptosis in human hepatoma cell lines by chemotherapeutic drugs via Fas-dependent and Fas-independent pathways. Hepatology. 29: 101-110.

Ju, Y.H., Clausen, L.M., Allred, K.F., Almada, A.L. and Helferich, W.G. 2004 . beta-Sitosterol, beta-Sitosterol Glucoside, and a Mixture of beta-Sitosterol and beta-Sitosterol Glucoside Modulate the Growth of Estrogen-Responsive Breast Cancer Cells In Vitro and in Ovariectomized Athymic Mice. The Journal of nutrition. 134: 1145-1151.

Karaca, K., Sharma, J.M. and Nordgren, R. 1995. Nitric oxide production by chicken macrophages activated by Acemannan, a complex carbohydrate extracted from Aloe vera. International journal of immunopharmacology. 17: 183-188.

Koschutnig, K., Heikkinen, S., Kemmo, S., Lampi, A.M., Piironen, V. and Wagner, K.H. 2009. Cytotoxic and apoptotic effects of single and mixed oxides of beta-sitosterol on HepG2-cells. Toxicology in vitro : an international journal published in association with BIBRA. 23: 755-762.

Krumbiegel, G., and Schulz, H.U. 1993. Rhein and aloe-emodin kinetics from senna laxatives in man. Pharmacology. 47 Suppl 1: 120-124.

Kumar, S., Matharasi, D.P., Gopi, S., Sivakumar, S. and Narasimhan, S. 2010. Synthesis of cytotoxic and antioxidant Schiff's base analogs of aloin. Journal of Asian natural products research. 12: 360-370.

Kuo, P.L., Lin, T.C., and Lin, C.C. 2002. The antiproliferative activity of aloe-emodin is through p53-dependent and p21-dependent apoptotic pathway in human hepatoma cell lines. Life sciences. 71: 1879-1892.

Lai, M.Y., Hour, M.J., Wing-Cheung Leung, H., Yang, W.H. and Lee, H.Z. 2007. Chaperones are the target in aloe-emodin-induced human lung nonsmall carcinoma H460 cell apoptosis. European journal of pharmacology. 573: 1-10.

Lee, H.Z. 2001. Protein kinase C involvement in aloe-emodin- and emodininduced apoptosis in lung carcinoma cell. British journal of pharmacology. 134: 1093-1103.

Lee, H.Z., Yang, W.H., Hour, M.J., Wu, C.Y., Peng, W.H., Bao, B.Y., Han, P.H. and Bau, D.T. 2010. Photodynamic activity of aloe-emodin induces resensitization of lung cancer cells to anoikis. European journal of pharmacology. 648: 50-58.

Lee, M.-J., Yoon, S.-H., Lee, S.-K., Chung, M.-H., Park, Y.-I., Sun, C.-K., Choi, J.-S. and Kim, K.-W. 1995. In vivo angiogenic activity of dichloromethane extracts of Aloe Vera Gel. Arch Pharm Res. 18: 332-335.

Lin, J.G., Chen, G.W., Li, T.M., Chouh, S.T., Tan, T.W. and Chung, J.G. 2006. Aloe-emodin induces apoptosis in T24 human bladder cancer cells through the p53 dependent apoptotic pathway. The Journal of urology. 175: 343-347. 
Lin, M.L., Lu, Y.C., Chung, J.G., Li, Y.C., Wang, S.G., Wu, C.Y., Su, H.L. and Chen, S.S. 2010. Aloe-emodin induces apoptosis of human nasopharyngeal carcinoma cells via caspase-8-mediated activation of the mitochondrial death pathway. Cancer letters. 291: 46-58.

Lin, M.L., Lu, Y.C., Su, H.L., Lin, H.T., Lee,C.C., Kang, S.E., Lai, T.C., Chung, J.G. and Chen, S.S.. 2011. Destabilization of CAR mRNAs by aloe-emodin contributes to caspase-8-mediated p53-independent apoptosis of human carcinoma cells. Journal of cellular biochemistry. 112: 1176-1191.

Lissoni, P., Giani, L., Zerbini, S., Trabattoni, P. and Rovelli, F. 1998. Biotherapy with the pineal immunomodulating hormone melatonin versus melatonin plus aloe vera in untreatable advanced solid neoplasms. Natural immunity. 16: 27-33.

Lissoni, P., Rovelli, F., Brivio, F., Zago, R., Colciago, M., Messina, G., Mora, A. and Porro, G. 2009. A randomized study of chemotherapy versus biochemotherapy with chemotherapy plus Aloe arborescens in patients with metastatic cancer. In Vivo. 23: 171-175.

Lu, G.D., Shen, H.M., Chung, M.C. and Ong, C.N. 2007a. Critical role of oxidative stress and sustained JNK activation in aloe-emodin-mediated apoptotic cell death in human hepatoma cells. Carcinogenesis. 28: 19371945.

Lu, G.D., Shen, H.M., Ong, C.N. and Chung, M.C. 2007b. Anticancer effects of aloe-emodin on HepG2 cells: Cellular and proteomic studies. Proteomics. Clinical applications. 1: 410-419.

Lyman, G.H., Lyman, C.H. and Agboola, O. 2005. Risk models for predicting chemotherapy-induced neutropenia. The oncologist. 10: 427-437.

MacLennan, A.H., Wilson, D.H. and Taylor, A.W. 1996. Prevalence and cost of alternative medicine in Australia. Lancet. 347: 569-573.

Manitto, P., Monti, D. and Speranza, G. 1990. Studies on aloe. Part 6. Conformation and absolute configuration of aloins $\mathrm{A}$ and $\mathrm{B}$ and related 10-C-glucosyl-9-anthrones. Journal of the Chemical Society, Perkin Transactions 1: 1297-1300.

Marcus, D.M., and Grollman,A.P.2002. Botanical medicines--the need for new regulations. The New England journal of medicine. 347: 2073-2076.

Massague, J. 2004. G1 cell-cycle control and cancer. Nature. 432: 298-306.

McClendon, A.K., and Osheroff, N. 2007. DNA topoisomerase II, genotoxicity, and cancer. Mutation research. 623: 83-97.

McFarland, B., Bigelow, D., Zani, B., Newsom, J. and Kaplan, M. 2002. Complementary and alternative medicine use in Canada and the United States. American journal of public health. 92: 1616-1618.

Mijatovic, S., Maksimovic-Ivanic, D., Radovic, J., Miljkovic, D., Kaludjerovic, G.N., Sabo, T.J. and Trajkovic, V. 2005. Aloe emodin decreases the ERK-dependent anticancer activity of cisplatin. Cellular and molecular life sciences : CMLS. 62: 1275-1282.

Moghaddasi,S., and Verma,S.K.2011. Aloe vera their chemicals composition and applications: A review. Int J Biol Med Res. 2: 466-471. 
Molassiotis, A., Fernadez-Ortega, P., Pud, D., Ozden, G., Scott, J.A., Panteli, V., Margulies, A., Browall, M., Magri, M., Selvekerova, S., Madsen, E., Milovics, L., Bruyns, I., Gudmundsdottir, G., Hummerston, S., Ahmad, A.M., Platin, N., Kearney, N. and Patiraki, E. 2005. Use of complementary and alternative medicine in cancer patients: a European survey. Annals of oncology : official journal of the European Society for Medical Oncology / ESMO. 16: 655-663.

Moon, D.O., Kim, M.O., Choi, Y.H. and Kim, G.Y. 2008. beta-Sitosterol induces $\mathrm{G} 2 / \mathrm{M}$ arrest, endoreduplication, and apoptosis through the Bcl-2 and PI3K/Akt signaling pathways. Cancer letters. 264: 181-191.

Moon, D.O., Lee, K.J., Choi, Y.H. and Kim, G.Y. 2007. Beta-sitosterolinduced-apoptosis is mediated by the activation of ERK and the downregulation of Akt in MCA-102 murine fibrosarcoma cells. International immunopharmacology. 7: 1044-1053.

Mueller, S.O., Stopper, H., and Dekant, W. 1998. Biotransformation of the anthraquinones emodin and chrysophanol by cytochrome P450 enzymes. Bioactivation to genotoxic metabolites. Drug metabolism and disposition: the biological fate of chemicals. 26: 540-546.

Muller, S.O., Eckert, I., Lutz, W.K. and Stopper, H.. 1996. Genotoxicity of the laxative drug components emodin, aloe-emodin and danthron in mammalian cells: topoisomerase II mediated? Mutation research. 371: 165-173.

Nahin, R.L., Barnes, P.M., Stussman, B.J. and Bloom, B. 2009. Costs of complementary and alternative medicine (CAM) and frequency of visits to CAM practitioners: United States, 2007. National health statistics reports: $1-14$.

NCCAM.2011. What is complementary and alternative medicine? National Center for Complementary and Alternative Medicine. nccam.nih.gov/ health/whatiscam/ [accessed 1 April 2011].

Niciforovic, A., Adzic, M., Spasic, S.D. and Radojcic, M.B. 2007. Antitumor effects of a natural anthracycline analog (Aloin) involve altered activity of antioxidant enzymes in HeLaS3 cells. Cancer biology \& therapy. 6: 1200-1205.

Nusko, G., Schneider, B., Schneider, I., Wittekind, C. and Hahn, E.G. 2000. Anthranoid laxative use is not a risk factor for colorectal neoplasia: results of a prospective case control study. Gut. 46: 651-655.

Park, C., Moon, D.O., Ryu, C.H., Choi, B., Lee, W., Kim, G.Y. and Choi, Y.2008a. Beta-sitosterol sensitizes MDA-MB-231 cells to TRAIL-induced apoptosis. Acta pharmacologica Sinica. 29: 341-348.

Park, K.Y., Cho, E.J., Rhee, S.H., Jung, K.O., Yi, S.J. and Jhun, B.H. 2003. Kimchi and an active component, beta-sitosterol, reduce oncogenic H-Ras(v12)-induced DNA synthesis. Journal of medicinalfood. 6: 151-156.

Park, M.Y., Kwon, H.J. and Sung, M.K.2008b. Plasma, tissue and urinary levels of aloin in rats after the administration of pure aloin. Nutrition research and practice. 2: 17-21. 
Park, M.Y., Kwon, H.J. and Sung, M.K. 2009. Intestinal absorption of aloin, aloe-emodin, and aloesin; A comparative study using two in vitro absorption models. Nutrition research and practice. 3: 9-14.

Patel, P.M., Selby, P.J., Deacon, J., Chilvers, C. and McElwain, T.J. 1989. Anthraquinone laxatives and human cancer: an association in one case. Postgraduate medical journal. 65: 216-217.

Pecere, T., Gazzola, M.V., Mucignat, C., Parolin, C., Vecchia, F.D., Cavaggioni, A., Basso, G., Diaspro, A., Salvato, B., Carli, M. and Palu, G. 2000. Aloe-emodin is a new type of anticancer agent with selective activity against neuroectodermal tumors. Cancer research. 60: 2800-2804.

Peng, S.Y., Norman, J., Curtin, G., Corrier, D., McDaniel, H.R. and Busbee, D. 1991. Decreased mortality of Norman murine sarcoma in mice treated with the immunomodulator, Acemannan. Molecular biotherapy. 3: 79-87.

Reynolds, T., and Dweck, A.C. 1999. Aloe vera leaf gel: a review update. Journal of ethnopharmacology. 68: 3-37.

Schorkhuber, M., Richter, M., Dutter, A., Sontag, G. and Marian, B. 1998. Effect of anthraquinone-laxatives on the proliferation and urokinase secretion of normal, premalignant and malignant colonic epithelial cells. Eur J Cancer. 34: 1091-1098.

Sheets, M.A., Unger, B.A., Giggleman, G.F. Jr., and Tizard, I.R.. 1991. Studies of the effect of acemannan on retrovirus infections: clinical stabilization of feline leukemia virus-infected cats. Molecular biotherapy. 3: 41-45.

Suboj, P., Babykutty, S., Valiyaparambil Gopi, D.R., Nair, R.S., Srinivas, P. and Gopala, S. 2012. Aloe emodin inhibits colon cancer cell migration/angiogenesis by downregulating MMP-2/9, RhoB and VEGF via reduced DNA binding activity of NF-kappaB. European journal of pharmaceutical sciences : official journal of the European Federation for Pharmaceutical Sciences. 45: 581-591.

Tabolacci, C., Lentini, A., Mattioli, P., Provenzano, B., Oliverio, S., Carlomosti, F. and Beninati, S. 2010. Antitumor properties of aloe-emodin and induction of transglutaminase 2 activity in B16-F10 melanoma cells. Life sciences. 87: 316-324.

Tabolacci, C., Oliverio, S., Lentini, A., Rossi, S., Galbiati, A., Montesano, C., Mattioli, P., Provenzano, B., Facchiano, F. and Beninati, S. 2011. Aloe-emodin as antiproliferative and differentiating agent on human U937 monoblastic leukemia cells. Life sciences. 89: 812-820.

Tascilar, M., de Jong, F.A., Verweij, J. and Mathijssen, R.H. 2006. Complementary and alternative medicine during cancer treatment: beyond innocence. The oncologist. 11: 732-741.

Tough, S.C., Johnston, D.W., Verhoef, M.J., Arthur, K. and Bryant, H. 2002. Complementary and alternative medicine use among colorectal cancer patients in Alberta, Canada. Alternative therapies in health and medicine. 8: 54-56, 58-60, 62-54. 
Ulbricht, C., Armstrong. J., Basch, E., Basch, S., Bent, S., Dacey, C., Dalton, S., Foppa, I., Giese, N., Hammerness, P., Kirkwood, C., Sollars,D.,Tanguay-Colucci,S. and Weissner, W.2007. An evidence-based systematic review of Aloe vera by the natural standard research collaboration. Journal of herbal pharmacotherapy. 7: 279-323.

van Maanen, J.M., Retel, J., de Vries, J. and Pinedo, H.M. 1988. Mechanism of action of antitumor drug etoposide: a review.Journal of the National Cancer Institute. 80: 1526-1533.

VPL. 2011. Carravet ${ }^{\circledR}$ acemannan immunostimulant. . Veterinary Products Laboratories. vpl.com/product.php?catmain $=\&$ mainkey $=\&$ pid $=80 \&$ key $=\mathrm{v} \& \mathrm{cat}=$ Wound\%20Management [accessed 6 April 2011].

Williams, M.S., Burk, M., Loprinzi, C.L., Hill, M., Schomberg, P.J., Nearhood, K., O'Fallon, J.R., Laurie, J.A., Shanahan, T.G., Moore, R.L., Urias, R.E., Kuske, R.R., Engel, R.E. and Eggleston, W.D. 1996. Phase III double-blind evaluation of an aloe vera gel as a prophylactic agent for radiation-induced skin toxicity. International journal of radiation oncology, biology, physics. 36: 345-349.

Xiao, B., Guo, J., Liu, D. and Zhang, S. 2007. Aloe-emodin induces in vitro $\mathrm{G} 2 / \mathrm{M}$ arrest and alkaline phosphatase activation in human oral cancer KB cells. Oral oncology. 43: 905-910.

Zhang, L., and Tizard, I.R. 1996. Activation of a mouse macrophage cell line by acemannan: the major carbohydrate fraction from Aloe vera gel. Immunopharmacology. 35: 119-128.

Zhao, Y., Chang, S.K., Qu, G., Li, T. and Cui, H. 2009. Beta-sitosterol inhibits cell growth and induces apoptosis in SGC-7901 human stomach cancer cells. Journal of agricultural and food chemistry. 57: 5211-5218. 
